\title{
Autoimagem e a relação com a vida sexual das mulheres
}

\author{
Self-image and the relationship with women's sexual life \\ Autoimagen y relación con la vida sexual de las mujeres \\ Nathalia Jung Ferreira Malta ${ }^{1 *}$, Maria Elisa Wotzasek Cestari ${ }^{1}$, Rosely Jung Pisicchio ${ }^{1}$, Keli Regiane \\ Tomeleri da Fonseca Pinto ${ }^{1,}$ Fabiana Fontana Medeiros ${ }^{1}$.
}

\begin{abstract}
RESUMO
Objetivo: Identificar a relação da autoimagem feminina com a atividade sexual e o prazer sexual. Métodos: Trata-se de um estudo descritivo com abordagem qualitativa. Os dados foram analisados pela técnica de Análise de Conteúdo proposto por Bardin. Resultados: A Imagem Corporal foi entendida como a construção corporal percebida pela mulher. Algumas mulheres idealizaram o corpo como um corpo jovem e com padrão midiático. Sentimento de sofrimento com relação à percepção de outras pessoas diante de um corpo fora dos padrões culturais estabelecidos pela sociedade e a dificuldade para encontrar roupas fabricadas para mulheres acima do peso considerado adequado e modelagens apropriadas. Quanto à relação da autoimagem com a atividade sexual e o prazer sexual, as participantes referiram vergonha de seu corpo, interferindo na sua relação sexual. Conclusão: $O$ presente estudo evidenciou que o corpo não revela apenas componentes estruturais, mas também fatores sociais, psicológicos, culturais e sexuais que adquirem singularidade. Por fim, os padrões corporais e a sua relação com a vida sexual são modulados em cada época e sempre estarão em movimento, sendo um desafio para a promoção da saúde da mulher.
\end{abstract}

Palavras-chave: Sexualidade, Assistência integral à saúde da mulher, Autoimagem.

\begin{abstract}
Objective: To identify the relationship between female self-image and sexual activity and sexual pleasure. Methods: This is a descriptive study, with a qualitative approach. The data were analyzed using the Content Analysis technique, proposed by Bardin. Results: Body image was understood as the body construction perceived by women. Some women idealized the body as a young body with a media standard. Feeling of suffering in relation to other people's perception of a body outside the cultural standards established by society and the difficulty in finding clothes manufactured for women overweight considered appropriate and appropriate modeling. The relationship between self-image and sexual activity and sexual pleasure, the participants mentioned shame about their body, interfering in their sexual relationship. Conclusion: The present study showed that the body reveals not only structural components, but also social, psychological, cultural and sexual factors that acquire uniqueness. Finally, body patterns and their relationship with sexual life are modulated in each season and will always be in motion, being a challenge for the promotion of women's health.
\end{abstract}

Keywords: Sexuality, Comprehensive care to women's health, Self concept.

\section{RESUMEN}

Objetivo: Identificar la relación entre la autoimagen femenina y la actividad sexual y el placer sexual. Métodos: Se trata de un estudio descriptivo, con enfoque cualitativo. Los datos fueron analizados mediante la técnica de Análisis de Contenido, propuesta por Bardin. Resultados: La imagen corporal se entendió como

${ }^{1}$ Universidade Estadual de Londrina (UEL), Londrina - PR. *E-mail: nathalia_fferreira@hotmail.com 
la construcción corporal percibida por las mujeres. Algunas mujeres idealizaron el cuerpo como un cuerpo joven con un estándar mediático. Sensación de sufrimiento en relación a la percepción ajena de un cuerpo fuera de los estándares culturales establecidos por la sociedad y la dificultad para encontrar prendas confeccionadas para mujeres con sobrepeso consideradas adecuadas y de modelado apropiado. La relación entre la imagen de sí mismos y la actividad sexual y el placer sexual, los participantes mencionaron vergüenza sobre su cuerpo, interfiriendo en su relación sexual. Conclusión: El presente estudio mostró que el cuerpo revela no solo componentes estructurales, sino también factores sociales, psicológicos, culturales y sexuales que adquieren singularidad. Finalmente, los patrones corporales y su relación con la vida sexual se modulan en cada temporada y estarán siempre en movimiento, siendo un desafío para la promoción de la salud de la mujer.

Palabras clave: Sexualidad, Atención integral de salud de la mujer, Autoimagen.

\section{INTRODUÇÃO}

A busca de uma autoimagem feminina reconhecida como culturalmente apropriada parece incluir padrões de beleza que podem ser expressos de diferentes formas; o que é belo para uma população nem sempre é qualificado da mesma forma por outra e, na mulher, recaem os padrões construídos pela sociedade, tanto com relação ao corpo como aos comportamentos sexuais (RUSSO, 2005; FREITAS CMSM, et al., 2010).

Atualmente, as mulheres têm se preocupado com sua autoimagem de forma mais ampla, reconhecendo as alterações que ocorrem em seu corpo, como as hormonais, psicológicas, corporais e o envelhecimento, inclusive relacionado ao prazer sexual, extraindo o foco do ato sexual somente para a reprodução, colocando o corpo da mulher de forma mais ativa na experimentação da sua sexualidade (ALVES ERP, et al., 2015; SOUZA NS, et al., 2016).

A imagem corporal é conceituada como uma estrutura fisiológica responsável pelas organizações anatomofisiológicas, estrutural-libidinal e estrutural de forma individualizada para cada mulher, e que se modificam conforme o contexto social e histórico, podendo afetar os padrões instituídos pela sociedade sociológica (SKOPINSKI F, et al.,2015).

Entretanto, um corpo saudável nem sempre se traduz em um corpo adequado aos padrões de beleza instituídos pela sociedade. Esta uniformização do que se entende por ideal e belo parece ter um forte poder de persuasão, o que indica a necessidade de um corpo feminino padronizado, que pode resultar em adoecimento, visto que a busca para se adequar aos padrões culturais nem sempre segue caminhos saudáveis (BARBOSA MR, et al., 2011).

Em meados do século XIX, eram observadas, nas manifestações artísticas, em especial nas pinturas, figuras de corpos volumosos, pois naquela época o padrão de beleza do corpo feminino era aquele que tinha maior peso, característico da população nobre e dominante. Esse padrão se perpetuou até meados dos anos 30, quando o padrão de beleza começou a mudar, redirecionando o foco da beleza ao corpo magro (FREITAS CMSM, et al., 2010).

A obesidade, que tinha uma relação com a beleza, passa a ser definida, no século XX, como um sinal de doença, interpretada como falta de controle, compulsão e autoindulgência; em contrapartida, o corpo magro era visto como autodisciplina, domínio próprio sobre o seu corpo (FREITAS CMSM, et al., 2010; FERREIRA FR, 2010).

O padrão de corpo ideal magro começou a ser divulgado em escala mundial, atingindo milhares de pessoas, contribuindo para a perpetuação de um padrão social e levando a diversos distúrbios da imagem corporal e compuções pela busca de um corpo considerado ideal (GOULART CF e CARVALHO PA, 2018).

O processo de empoderamento e de autonomia feminina em relação aos padrões de beleza demanda um grande esforço de reconstrução social, especialmente pela busca da igualdade dos direitos femininos e pela desnaturalização dos diferentes tipos de violência contra a mulher na sociedade (BARBOSA HHG e JUNIOR VAA, 2017). 
Empiricamente, a preocupação com a autoimagem corporal parece influenciar a sexualidade da mulher, interferindo na segurança feminina da exposição do corpo no ato sexual, causando dificuldade no alcance do prazer sexual. Entretanto, há uma lacuna no conhecimento sobre a temática e uma a necessidade de compreender os fatores que interferem na satisfação com o corpo e na autoestima e sua relação com a vida sexual da mulher. Assim, este estudo objetivou identificar a relação da autoimagem feminina com a atividade sexual e o prazer sexual.

\section{MÉTODOS}

Trata-se de um estudo descritivo com abordagem qualitativa. Este estudo faz parte de um projeto de pesquisa maior intitulado Estratégias de prevenção do HPV e sua relação com o câncer, sendo este um recorte dos resultados. O cenário do estudo foi uma Unidade Básica de Saúde (UBS) da região norte do Paraná.

Participaram do estudo oito mulheres pertencentes ao programa de prevenção de câncer de mama e colo uterino. Foram utilizados como critérios de inclusão: mulheres que participavam do programa de prevenção. Foram escolhidas aleatoriamente e informadas sobre os objetivos do estudo e o sigilo das informações. Com a concordância, solicitava-se a assinatura do termo de consentimento livre e esclarecido. A coleta de dados ocorreu no mês de novembro de 2018 por meio de entrevista agendada e individual em um consultório na UBS, garantindo privacidade e o mínimo de interferências. Foi utilizado um formulário com perguntas semiestruturadas, com idade, situação conjugal, número de filhos, IMC (índice de massa corpórea), peso e altura.

As questões norteadoras utilizadas na entrevista foram: "Como você vê o seu corpo? Descreva para mim"; "Para você, o que seria um corpo perfeito?"; "Você se sente satisfeita com o seu corpo?"; "Você se sente satisfeita com o seu corpo durante a relação sexual?".

A duração média das entrevistas foi de 25 minutos, considerando a interação inicial e a entrevista propriamente dita. As entrevistas foram gravadas e transcritas na íntegra pelas pesquisadoras, sendo realizado correções do português e vícios da linguagem, não interferindo no sentido da fala. As codificações foram realizadas com a letra $\mathrm{M}$ (mulher) de acordo com a ordem de realização como $M 1, M 2$, e assim, sucessivamente, respeitando a condição de anonimato das participantes.

Os dados foram analisados pela técnica de Análise de Conteúdo proposto por Bardin, contemplando as fases pré-análise, exploração do material e tratamento dos resultados (inferência e interpretação) (BARDIN L, 2011). Os dados foram coletados até sua saturação e o alcance do objetivo proposto.

Este estudo foi aprovado pelo Comitê de Ética em Pesquisa da Universidade Estadual de Londrina com número CAAE 65211816.3.0000.5231.

\section{RESULTADOS}

A populaçaõ de estudo foi composta por oito mulheres com idade média de 36,6 anos, Quatro mulheres referiram ter ensino médio completo, seis mulheres eram casadas ou tinha união estavel. Das oito mulheres entrevistadas, duas mulheres apresentavam IMC considerado como peso ideal, três mulheres foram categorizadas como sobrepeso e outras três classificadas como obesidade grau I, obtendo $75 \%$ da nossa população com o peso acida do considerado ideal pelo IMC. O peso médio da população estudada foi de $65.25 \mathrm{~kg}$ e a altura foi de $1.64 \mathrm{~cm}$.

Após a análise das falas, elas foram agrupadas em duas categorias: 1. Imagem corporal e idealização do corpo feminino; 2. A relação da autoimagem com a atividade sexual e o prazer sexual.

\section{Imagem corporal e idealização do corpo feminino}

A Imagem Corporal foi entendida como a construção corporal percebida pela mulher. Algumas mulheres idealizaram o corpo como um corpo jovem e com padrão midiático. 
"Um corpo perfeito talvez seja de uma mulher mais jovem, que tenha tudo no lugar. Ela tem um corpo perfeito, né?!" (M1).

"Corpo de atriz é perfeito, tem bunda bonita, seios bonitos, tudo bonito" (M6).

"Seria imperfeito um peso muito alto (...). Acho que não teria um corpo perfeito, mas sim um peso equilibrado. Isso seria o ideal” (M7).

"Sinceramente eu não me sinto satisfeita com o meu corpo. Se me perguntasse se eu gostaria de mudar eu responderia: sim! Queria ser mais magrinha” (M8).

Entretanto, a insatisfação com o corpo também esteve presente em uma das mulheres que, em sua percepção, se considerava magra.

"Eu ando muito magra, me olho no espelho e me dá agonia. Vejo muito isso, tem que engordar um pouquinho. Para tirar foto eu olho e não me acho bonita, às vezes me olho no espelho e não me acho bonita também" (M6).

Outras mulheres idealizaram o corpo como um corpo saudável.

"Minha autoestima foi lá em cima depois que comecei a fazer academia” (M3).

"Para mim o perfeito é o interior. Para mim o perfeito é ter saúde, fisicamente para mim não importa, mas tem que ver como está sua saúde, para mim não importa se você está gordinho ou magro de mais, o que importa é a saúde" (M4).

Em algumas falas surgiu o sentimento de sofrimento com relação à percepção de outras pessoas diante de um corpo fora dos padrões culturais estabelecidos pela sociedade.

"Muitas pessoas questionam: Nossa você precisa emagrecer! Porque a barriga é desse tamanho?!" Me sinto mal. É terrível!! Você nunca fala para uma mulher que ela está gorda" (M7).

"Eu acho que tem padrão. Podemos até falar que não tem um padrão, mas tem! Eu acho que as gordinhas sofrem para comprar roupa e as pessoas têm preconceitos. Eu acho que tem que mudar. Eles colocam um padrão, que somos gordos porque comemos, mas nem sempre é assim, muitas vezes não é gordo porque come, tem uma série de outras coisas, ser gorda é fácil, difícil é ser eu" (M8).

Ressaltaram-se também as percepções das limitações que o excesso de peso acarreta no dia a dia das mulheres.

"Eu não quero ser magra porque as outras pessoas são magras. Eu quero poder vestir uma roupa sem me preocupar. Você não tem mais pique para fazer as coisas. Você anda meia quadra parece que correu $10 \mathrm{~km}$ (...). Me atrapalha bastante" (M2).

"Eu comecei a notar que para caminhar ou ter relação sexual eu fico mais ofegante, não me vejo mais tão vaidosa" (M5).

"Tem momentos que eu não me sinto bem, vou caminhar e já me sinto cansada, para trabalhar já é difícil” (M7).

A dificuldade para encontrar roupas fabricadas para mulheres acima do peso considerado adequado e modelagens apropriadas é uma constante nas falas.

"Eu sempre fui muito de comprar roupa. Hoje em dia nem tem numeração para mim. Faz tempo que não saio para comprar roupas principalmente depois que dei essa engordada" (M2).

"Conforme a roupa que eu coloco não me sinto bem. Eu sempre uso roupa larga para poder esconder a barriga” (M7). 
"Você vê em uma propaganda hoje tudo magrinha. Eu fiquei muito brava quando a vendedora estava me empurrando aqueles vestidos de senhora, eu estava uns $10 \mathrm{~kg}$ acima do peso, eu briguei com ela, falei: eu sei que sou gorda, mas não precisa ficar empurrando esses vestidos(...). Você chega em uma vitrine só tem aquele vestido para magrinha, dificilmente vai achar aquele vestido da vitrine para uma pessoa gordinha. Não tem!" (M8).

As falas demonstraram que a ambição do corpo perfeito tem diferentes perspectivas de dependência, como ter condições financeiras favoráveis, ter saúde adequada ou aceitar seu corpo como ele se apresenta, exibindo a singularidade de cada mulher.

"Só se você for rica para manter o corpo do jeito que você quer ou queria que fosse" (M1).

"Estar bem de saúde, porque não adianta nada estar bem por fora e ter problema por dentro" (M4).

"Eu acho que um corpo perfeito não é eu ser magra, é eu me aceitar. Como eu não me aceito nesse estilo, por isso eu acho que o problema está no meu psicológico, basta eu me aceitar! Como a vida inteira eu fui magra, eu tenho aquele psicológico, eu posso voltar a ser" (M5).

"Eu estou acima do peso. Nunca estamos contentes, porque se emagrece, emagrece de mais, se engorda, engorda de mais. Eu desconto tudo na comida, eu colocava culpa na tireoide. Eu já estive mais feliz, mas é o que tem para hoje, né?! Temos que gostar do jeito que a gente é!" (E8).

Algumas mulheres identificaram características de uma imagem corporal ideal como ausência de alterações fisiológicas no corpo, como celulite e estrias, sendo elas consideradas um "defeito" no corpo feminino.

"Nós não somos perfeitos, temos celulite, estrias, é normal. Mas as pessoas acham isso um absurdo" (M3).

"Eu acho que não existe um corpo perfeito, todo mundo tem um defeitinho" (M6).

Algumas mulheres relataram que o corpo pode ser capaz de registrar a trajetória de vida de uma mulher. Neste estudo, o corpo não foi visto apenas como um esqueleto que tem ossos e músculos, mas sim um corpo que conta a história de cada mulher.

"Quando me olho no espelho vejo um corpo de uma mulher que já teve filho, com algumas estrias e o seio caído. Eu me vejo como uma mulher normal pela minha idade. Eu já fui mocinha, já tive um corpo maravilhoso" (M1).

"Eu acho que sou satisfeita, pela minha idade, 50 anos, eu vejo que estou bem fisicamente, eu gosto do que vejo" (M4).

"Sempre fui magra, nunca engordei nas minhas gestações, eu sempre tive um corpo bonito, sempre gostei e agora tenho me sentido péssima com relação ao meu corpo de não gostar de nada" (M5).

A sobrecarga emocional devido ao acúmulo de responsabilidade com relação à criação dos filhos e da manutenção financeira da casa fez com que o autocuidado fosse deixado em segundo plano.

"Meu marido viaja muito, tenho que me virar sozinha. É estressante. Eu sou pai e mãe. Fica tudo nas minhas costas. Salgado e doce eu faço de madrugada. Trabalho até a hora que precisar, depende da encomenda. Sempre vou me reinventado. Hoje eu não tenho tempo e nem dinheiro. Eu abro mão de mim e vou deixando para escanteio" (M2). 


\section{A relação da autoimagem com a atividade sexual e o prazer sexual}

As participantes referiram vergonha de seu corpo, interferindo na sua relação sexual.

"A forma que eu me vejo vai interferir ali na hora do sexo, lógico que a gente quer ter seios firminhos, um corpo mais bonito para o esposo" (M1).

"Sinto vontade, mas hoje tenho muita vergonha. Eu não me sinto bem assim(...)" (M2).

"Acho que o peso atrapalha! Eu fico retraída, não tenho aquela disposição, aquele ânimo para estar praticando a relação sexual! Tenho um desconforto para fazer os movimentos. Às vezes eu fico com vergonha de me ver nua e aquela barriga ali incomoda e atrapalha. Às vezes passa 15 dias, um mês sem ter relação sexual" (M7).

Em contrapartida, outras participantes relataram que os parceiros não sentem diferença ou objeção à forma estrutural do corpo, assim não interferindo na atividade sexual.

"O marido da gente nem liga. Para ele é indiferente do jeito que eu era ou do jeito que eu estou agora. Muitas vezes ficamos muito tempo sem um procurar o outro, mas isso não nos afeta como casal" (M2).

"Me sinto satisfeita na relação sexual. Ele me põe para cima, diz que estou linda. Me sinto satisfeita na relação sexual" (M6).

As alterações fisiológicas do corpo de acordo com a idade da mulher e as intervenções cirúrgicas ginecológicas foram citadas como fatores que parecem interferir no desejo sexual e na diminuição da lubrificação vaginal, podendo provocar dispareunia.

"Estou entrando na menopausa, então eu não tenho apetite sexual. Muitas vezes que tenho relação sexual, eu não sinto nada praticamente, faço mais para agradar meu esposo" (M1).

"Depois que eu tive meu parto normal, o médico deu um ponto que ele não devia ter dado, dependendo do jeito, eu sinto um pouco de dor. Mesmo que eu esteja com vontade, não é uma dor insuportável, mas é uma dor que eu não sentia, então me incomoda" (M2).

"Faz três anos que não menstruo. Eu não senti diferença na relação sexual. Mas a lubrificação diminuiu um pouco" (M4).

"Dificilmente tenho prazer na relação sexual. Vou ficando sem lubrificação, daí fica aquele negócio seco, às vezes machuca e dói. A falta de desejo me incomoda bastante" (M7).

Algumas mulheres destacaram como positivo para a satisfação sexual sentirem-se desejadas pelo parceiro, ou seja, quando têm um relacionamento sexual baseado numa relação de complementaridade.

"Tenho satisfação sexual quando me sinto desejada. Eu me sinto satisfeita em satisfazer ele também. Vejo ele satisfeito, então eu também me satisfaço" (M4).

"Eu nunca tive medo na relação, "ah eu não gosto do meu corpo, quero só luz apagada", nunca tive esse problema. Me sinto satisfeita na relação sexual. Ele sempre fala elogios. Me sinto orgulhosa. É raridade, me ajuda a ter autoestima lá em cima" (M6).

\section{DISCUSSÃO}

A idealização do corpo feminino remete a um conjunto imaginário de aspirações e percepções que definem a imagem corporal a ser alcançada na busca pelo corpo ideal (GOULART CF; CARVALHO PA, 2018). Um estudo avaliou a prevalência da insatisfação com a imagem corporal no grupo de homens e mulheres, 
identificando que os indivíduos com excesso de peso e risco de doenças cardiovasculares apresentam maior prevalência à insatisfação corporal do que aqueles com estado nutricional adequado; entretanto, o estudo avaliou que, mesmo quando as mulheres encontram-se dentro dos padrões considerados normais do peso corporal, elas se encontram insatisfeitas com sua imagem corporal, ressaltando a busca incessante pela idealização do corpo perfeito nas mulheres (SILVA LPR, et al., 2019).

No presente estudo, alguns participantes demonstraram que a imagem corporal é entendida como um corpo jovem com padrão midiático; entretanto ressalta que a busca por um corpo ideal é gradativamente inserida nos meios de comunicação como internet, televisão, rádio, revistas e jornais, de forma com que os padrões da sociedade definem as formas corporais apresentadas por toda a população (DOURADO CS, et al., 2018; BARBOSA MR, et al., 2011; GOULART CF e CARVALHO PA., 2018).

Alguns estudos mostram que desde muito cedo, os jovens trazem consigo a idealização de um corpo perfeito que muitas vezes é inexistente ou impossível de ser alcançado, gerando sofrimento, distúrbios alimentares, depressão e distorção da autoimagem. Com isso, ocorre uma ilusão de que existe apenas um padrão de beleza, sem levar em consideração a diversidade de corpos dentro de uma sociedade, sendo compatível com as falas apresentadas neste estudo (GOULART CF e CARVALHO PA, 2018).

Foram identificadas nas falas as limitações que o sobrepeso acarreta no cotidiano das mulheres entrevistadas, sendo compatível com a literatura que ressalta as limitações que o excesso de peso pode causar no cotidiano das mulheres, decorrente de transtornos alimentares, compulsões, depressão, baixa autoestima, comparação social, ansiedade e diminuição da qualidade de vida (SKOPINSKI F, et al., 2015).

A imagem corporal é construída de forma multidimensional, influenciada por diversos fatores. Desta forma, a roupa interage com o corpo e constrói uma aparência coerente com as expectativas da sociedade. $O$ acesso a uma variedade de roupas com estilos diferentes favorece a expressão mais completa de si mesmo (MARCELJA KG, 2015). Entretanto, neste estudo, algumas mulheres referiram dificuldade de ter roupas adequadas para o tamanho e forma do corpo, indicando a necessidade de um olhar para esse segmento por parte dos confeccionistas da moda, valorizando as curvas ao invés de disfarçar ou esconder.

Algumas participantes referiram que o corpo vai além de uma estrutura óssea ou muscular, do bonito ou feio, de ter ou não estrias, de ser gordo ou magro; o corpo carrega o verbo "eu", que vem antes de um status ou um padrão social. Ele tem uma trajetória, singularidade, individualidade, beleza e significado. As marcas no corpo podem ser causadas por momentos de alegria, marcas de uma vida de luta ou apenas marcas do passar dos anos, mas cada corpo tem suas memórias e marcas da vida (DANTAS JB, 2011; DOURADO CS, et al., 2018).

Foi observada também a sobrecarga emocional devido ao acúmulo de atividades cotidianas da vida da mulher. A literatura, de fato, evidencia que a mulher tem conquistado o seu espaço no mundo econômico, mas não a isenta das funções atribuídas, como cuidar da casa e da família. A inserção das mulheres no âmbito trabalhista representa uma revolução incompleta, pois elas ainda assumem praticamente sozinhas as atividades domésticas e a criação dos filhos, como demonstrado nas falas (SOUSA LP e GUEDES DR, 2016).

O enfrentamento da dupla jornada de trabalho pode levar a uma desordem hormonal causada pelo estresse contínuo e a carga de deveres, desencadeando vários transtornos psicológicos, como a depressão (COUTINHO MEN, et al., 2015). A prática de atividade física foi desvelada como uma estratégia para a elevação da autoestima; entretanto, a concretização da realização do exercício físico é uma barreira na vida da mulher diante das inúmeras atividades diárias a serem realizadas.

Uma revisão sistemática da literatura descreveu inúmeros fatores aos entraves à prática do exercício físico em países árabes, considerado como fatores não motivadores à sua realização: o clima quente para realização de caminhadas ao ar livre, a falta de conhecimento sobre comportamento saudável, atividades sociais com foco no sedentarismo e lanches não saudáveis, além de fatores culturais e religiosos que podem ser impedimento à sua realização. $O$ estudo ressalta ainda que a percepção de saúde muitas vezes se limita à higiene, descanso e dieta, não sendo praticada a atividade física (SHARARA E, et al., 2018). 
Observa-se na literatura que a obesidade contribui para o desenvolvimento de algumas disfunções, como alterações no ciclo menstrual, disfunções sexuais, redução na fertilidade, diminuição do desejo sexual, da excitação e do orgasmo, interferindo na vida sexual e favorecendo uma desordem psíquica e emocional sendo compatível com os achados nesta pesquisa, salientado a escassez de artigo publicados em âmbito nacional e internacional, sendo este um tema (CECÍLIO HPM, et al., 2014).

\section{CONCLUSÃO}

Conclui-se que o corpo não revela apenas um componente da imagem, mas sua representação social, psicológica, cultural e sexual, que é específica a cada ser humano. Ressalta-se a influência da sociedade e das mídias sociais no impacto do padrão de beleza à vida da mulher, que resulta em distorção da autoimagem corporal. O estudo evidenciou que a busca pelo corpo ideal magro e sem defeitos reflete em uma sobrecarga emocional, interferindo negativamente na vida sexual das mulheres e na sua autoimagem.

\section{REFERÊNCIAS}

1. ALVES ERP, et al. Climatério: a intensidade dos sintomas e o desempenho sexual. Texto Completo Enfermagem, 2015; 24(1):64-71.

2. ARAUJO LS, et al. Preconceitos frente à obesidade: representações sociais veiculadas pela mídia impressa. Arquivo Brasileiro de Psicologia, 2018; 70(1): 69-85.

3. BARBOSA HHG, JUNIOR VAA. Desigualdade de gênero: restrições à autonomia da mulher. Revista de ciência jurídica, 2017; 22(1): 240-271.

4. BARBOSA MR, et a. Um olhar sobre o corpo: o corpo ontem e hoje. Psicologia e sociedade; 2011 23(1):24-34.

5. BARDIN L. Análise de conteúdo. São Paulo: Edições 70; 2011

6. CECILIO HPM, et al. Percepções de mulheres obesas sobre a sexualidade. Rev. Min. Enfermagem, 2014;18(4): 955960.

7. COUTINHO MEM, et al. Aspecto biológico e psicossocial da depressão relacionado ao gênero feminino. Rev. Brasileira de neurologia e psiquiatria,2015;19(1):49-57.

8. DANTAS JB. Um ensaio sobre o culto ao corpo na contemporaneidade. Rev. Estudos e Pesquisa em Psicologia,2011;11(3): 898-912.

9. DOURADO CS, et al. Bady, culture and meaning. J. Hum Growth Dev,2018;28(2): 206-2012.

10. FERREIRA FR. Corpo feminino e beleza no século XX. ALCEU,2010;11( 21): 186-201.

11. FREITAS CMSM, et al. O padrão de beleza corporal sobre o corpo feminino mediante o IMC. Rev. Brasileira Educação Física, Esporte, 2010;24(.3): 389-404.

12. GOULART CF, CARVALHO PA. Corpo ideal e corpo real: a mídia e suas influências na construção da imagem corporal. Rev. Psicologia PT, 2018.

13. MARCELJA KG. A busca por uma identidade através da moda plus size. Congresso Internacional Comunicação e Consumo - COMUNICON, 2015.

14. O'MALLEY D, et al. Prevalence of and risk factors associated with sexual health issues in primiparous women at 6 and 12 months postpartum; a longitudinal prospective cohort study (the MAMMI study). BMC Pregnancy and Childbirth,2018;18(196).

15. SHARARA E, et al. Physical inactivity, gender and culture in Arab countries: a systematic assessment of the literature. BMC Public Health, 2018; 18(639).

16. SILVA LPR, et al. Dissatisfaction about body image and associated factors: a study of young undergraduate students. Einstein (São Paulo), 2019; 17(4).

17. SKOPINSKI F, RESENDE TL e SCHNEIDER RH. Imagem corporal, humor e qualidade de vida. Rev. Brasileira Geriatria e Gerontologia, 2015; 18(1): 95-105.

18. SOUSA LP, GUEDES DR. A desigual divisão sexual do trabalho: um olhar sobre a última década. Estudos avançados, 2016;30(84).

19. SOUZA AC DE, ALVARENGA MS. Insatisfação com a imagem corporal em estudantes universitários- Uma revisão integrativa. Rev. J. bras. Psiquiatria,2016; 65(3) 286-299.

20. SOUZA NS, et al. Maria Teresa Horta: Escrita feminina na poesia de um corpo liberto. Revista Interdisciplinar,2016; 26:123-136. 